\title{
Risk factors of postoperative delirium after cardiac surgery: a meta-analysis
}

\author{
Haiyan Chen ${ }^{1}$, Liang $\mathrm{Mo}^{2^{*}} \mathbb{D}$, Hongjuan $\mathrm{Hu}^{3^{*}}$, Yulan $\mathrm{Ou}^{3}$ and Juan $\mathrm{Luo}^{2}$
}

\begin{abstract}
Background: Postoperative delirium is a frequent event after cardiac surgery. This meta-analysis aimed to identify relevant risk factors.

Method: In this meta-analysis, all original researches regarding patients undergoing mixed types of cardiac surgery (excluding transcatheter procedures) and postoperative delirium were evaluated for inclusion. On July 28th 2020, we searched PubMed, Embase, Web of Science and Scopus. Data about name of first author, year of publication, inclusion and exclusion criteria, research design, setting, method of delirium assessment, incidence of delirium, odds ratio (OR) and corresponding 95\% confidence interval (Cl) of risk factors, and other information relevant was collected. OR and 95\% Cl were used as metrics for summarized results. Random effects model was applied.
\end{abstract}

Results: Fourteen reports were included with a total sample size of 13,286. The incidence of delirium ranged from 4.1 to $54.9 \%$. Eight risk factors were identified including aging, diabetes, preoperative depression, mild cognitive impairment, carotid artery stenosis, NYHA functional class III or IV, time of mechanical ventilation and length of intensive care unit stay.

Conclusion: In this study several risk factors associated with postoperative delirium after cardiac surgery were identified. Utilizing the information may allow us to identifying patients at high risk of developing postoperative delirium prior to delirium onset.

Keywords: Postoperative delirium, Cardiac surgery, Meta-analysis

\section{Background}

The very first documented report regarding postoperative delirium after cardiac surgery can be dated back to 1964 [1]. During the following half century, the topic has been discussed thoroughly. Many risk factors have been identified, many countermeasures have been proposed [2], and many high-quality researches have been conducted. At this time, we believe it is necessary to look back and make a brief, yet focused, summary of this topic.

\footnotetext{
* Correspondence: liangmohnhy@yeah.net; 1213887302@qq.com

${ }^{2}$ Department of Cardiothoracic Surgery, The First Affiliated Hospital of University of South China, Hengyang, China

${ }^{3}$ Nursing Department, The First Affiliated Hospital of University of South China, Hengyang, China

Full list of author information is available at the end of the article
}

According to The American Psychiatric Association's fifth edition of the Diagnostic and Statistical Manual of Mental Disorders (DSM-5), delirium is defined as a condition with following five key features: disturbance in attention and awareness; the disturbance develops over a short period of time and its severity tends to fluctuate during the course of a day; an additional disturbance in cognition; these mentioned disturbances cannot be better explained by other pre-existing neurocognitive disorders and do not occur in severely reduced arousal level such as coma; and there is evidence suggesting the disturbance is a direct result of another medical condition [3]. Delirium can be further classified into three subcategories: hyperactive, hypoactive, and mixed. Patients with hyperactive delirium presents hypervigilance, agitation and restlessness, while hypoactive delirium is

(c) The Author(s). 2021 Open Access This article is licensed under a Creative Commons Attribution 4.0 International License, which permits use, sharing, adaptation, distribution and reproduction in any medium or format, as long as you give appropriate credit to the original author(s) and the source, provide a link to the Creative Commons licence, and indicate if changes were made. The images or other third party material in this article are included in the article's Creative Commons licence, unless indicated otherwise in a credit line to the material. If material is not included in the article's Creative Commons licence and your intended use is not permitted by statutory regulation or exceeds the permitted use, you will need to obtain permission directly from the copyright holder. To view a copy of this licence, visit http://creativecommons.org/licenses/by/4.0/. The Creative Commons Public Domain Dedication waiver (http://creativecommons.org/publicdomain/zero/1.0/) applies to the data made available in this article, unless otherwise stated in a credit line to the data. 
characterized by lethargy with decreased movement and slowed mental activity [4]. In practice, hypoactive delirium often remains unrecognized due to its difficulty of detection [5]. It has been reported that post-operative delirium within first few days after surgery is associated with worsened prognosis including prolonged hospitalization, increased mortality [6], cognitive impairment, memory decline, need for long-term care ${ }^{7}$ and other unfavorable outcomes $[4,7,8]$ in cardiac surgery [9] as well as other types of surgery, though it is still not clear whether delirium is a direct cause of [these outcomes or the association is mediated by other unidentified common cause of both delirium and the outcomes. Several pharmacologic or non-pharmacologic methods have been proposed to prevent delirium including early mobilization, improving Intensive Care Unit (ICU) environment, prophylactic antipsychotic administration, preoperative statins use [10], or use dexmedetomidine instead of propofol for sedation [11]. However, the reliability of these suggestions is undermined by lack of evidence, conflicting results, small sample sizes and imprecise delirium assessment $[10,12,13]$.

Despite the effort made and the progress in surgical techniques during the past decades, the incidence of delirium after cardiac surgery remains between 26 and 52\% when estimated with rigorous methodology [10], and the caring for delirious patients remains a major challenge in the daily work of cardiac surgical ICU nurses. Regular screening and early identification, together with appropriate sedation, are crucial in delirium management [14]. However, it would be ideal if we can recognize patients with high delirium risk in advance and make preparations accordingly. Koster et al. and Lin et al. have summarized the risk factors of delirium after cardiac surgery in their previous systemic review [15] and meta-analysis [16], in which 10 and 25 original studies were included, leading to the revealment of a total of 27 and 33 risk factors, respectively. In the systemic review by Koster et al., 10 publications within the period January 1999 through December 2009 were reviewed, with 27 risk factors identified, while only 10 of them were mentioned more than once. Meta-analysis was not performed Koster et al., making the summarization merely qualitative. In the meta-analysis by Lin et al., which included literatures from 2008 to 2011, age increase, depression, stroke history and several other risk factors were identified, while the mixed use of univariate/multivariate results and RR/ OR values made the conclusions less robust mathematically. Besides, recent studies in which POD was diagnosed with Diagnostic and Statistical Manual of Mental Disorders Fifth Edition (DSM-V) were not analyzed by Koster et al. or Lin et al., suggesting the necessity of an updated summarization including original studies emerged from the most recent decade, given the rapid evolvement of clinical practice. The objective of this meta-analysis was to identify risk factors of delirium in patients undergoing mixed types of cardiac surgery excluding transcatheter procedures.

\section{Method}

\section{Search strategy and inclusion criteria}

To ensure the quality of this meta-analysis, inclusion criteria was decided before we carried out the search. These criteria were:

1. Only original researches are eligible for inclusion. Reviews, meta-analyses, study protocols, comments, editorials and errata shall not be considered for analysis.

2. Eligible studies must be carried out in cohorts containing more than one adult ( $>18$ years old) patient undergoing electiveopen-heart surgery, which was defined as any type of surgery in which an incision is made on chest and procedure is done on coronary artery, heart valve or myocardium, due to non-congenital heart disease.

3. Delirium must be assessed with one of the following tools: Diagnostic and Statistical Manual of Mental Disorders, Fourth or Fifth Edition (DSM-IV or DSM-V), Confusion Assessment Method (CAM), Confusion Assessment Method for the ICU (CAM-ICU), Intensive Care Delirium Screening Checklist (ICDSC) or other well-validated diagnostic standard based on the tools mentioned above. Researches focused on only one subtype of delirium (hyperactive delirium, hypoactive delirium or mixed delirium) shall not be included since the above tools recognize delirium of all subtypes but does not provide differential diagnosis among subtypes.

4. Risk factors for delirium must be assessed with odds ratio (OR) with 95\% confidence interval (CI). A research must present the results of both univariate and multivariate regression to be considered eligible for inclusion, since multivariate analysis results shall be used to identify variables eligible for meta-analysis and the actual metaanalysis shall be conducted on univariate analysis results.

5. Only full-text available literatures in English language are included.

6. For multiple reports on overlapping population, only the study with largest sample size shall be included to avoid including the same participants multiple times.

On July 28th 2020, a search was conducted on PubMed, Embase, Web of Science and Scopus in all past publications with following keywords: "delirium" AND 
("cardiac surgery" OR "heart surgery" OR "coronary artery bypass grafting" OR "cardiopulmonary bypass" OR "valve surgery") AND "risk factor"." The search yielded 268 results on PubMed, 559 results on Embase, 369 results on Web of Science and 448 results on Scopus. After removing duplicate entries automatically with Mendeley, 935 entries were screened by title, abstract or full text to identify eligible literatures. The screening process was independently performed by two investigators and discrepancies were resolved through discussion with a third reviewer.

\section{Data extraction and analysis}

Data extracted from selected literatures included information of authors, year of publication, sample size, inclusion and exclusion criteria, baseline features of patients, research design, research setting, method of delirium assessment, odds ratio (OR) and corresponding $95 \%$ confidence interval (CI) of risk factors, $p$ value, and other information considered relevant. A risk factor is eligible for meta-analysis if (1) it is identified as independent predictor in multivariate regression in at least one of included literatures; (2) its OR and corresponding 95\% confidence interval in univariate regression are reported in at least two of included literatures. We used only the OR and $\mathrm{CI}$ of risk factors resulted from univariate regression for analysis: a statement of statistical methodology applied was provided in Additional file 1. The identified risk factors shall be reported as preoperative, intraoperative and postoperative risk factors, since the traditional classification of predisposing and precipitating risk factors cannot be precisely recognized, mainly because of the complexity identifying the direct cause of POD. Thus, we chose a more practical classification to allow the results of this meta-analysis to be easily applied in clinical practice, facilitating the identification of patients at higher risk of POD.

Statistical analysis was conducted with meta package [17] in R. Between-study variance was evaluated with DerSimonian-Laird estimator. Heterogeneity among studies was measured with Cochran chi-square test and was considered present if $p$ value is less than 0.1. Heterogeneity statistic $\mathrm{I}^{2}$ was used to indicate level of heterogeneity. When $\mathrm{I}^{2}$ was lower than $25 \%$, studies analyzed were considered of low heterogeneity, while an $\mathrm{I}^{2}$ value greater than $50 \%$ indicated the presence of high heterogeneity. Pooled odds ratios and 95\% confidence intervals were evaluated with both fixed and random effects models; however, all conclusions of this metaanalysis were drawn from the random effects model results. Fixed effect analysis was done for reference only. For meta-analyses containing more than four studies, sensitivity analysis, in which studies were omitted once at a time to evaluate their impact to the final pooled result, and funnel plot analysis were performed.

\section{Risk of Bias and quality of evidence assessment}

Risk of bias assessment for each included study was performed using Newcastle-Ottawa Scale by two reviewers, independently. A third reviewer shall be invited to discussion to achieve consensus in case of disagreement [18]. Case-control studies were evaluated regarding case and control selection (4 stars), comparability between cases and controls (2 stars), and assessment of exposure (3 stars); while cohort studies were evaluated regarding selection of exposed and control cohorts (4 stars), comparability between cohorts ( 2 stars), and assessment of outcome (3 stars). Studies were considered to be at low risk if rated 7 stars or above, moderate risk if rated 4-6 stars, and high risk if less than 4 stars.

Quality of evidence assessment was performed through discussion among three reviewers using Grading of Recommendations, Assessment, Development and Evaluations (GRADE). For each result of this metaanalysis, one of the following ratings was assigned: High, where authors were confident that estimated effect was similar to the true effect; Moderate, where estimated effect was probably close to the true effect; Low, where the true effect might be different from the estimated effect; and Very low, where the true effect was probably markedly different from the estimated effect.

\section{Result}

Summary

A total of 14 studies met our inclusion criteria and was included in this meta-analysis [19-32]. The selection process was summarized with a flowchart (Fig. 1). The main features of these studies were summarized in Table 1. In summary, the studies eligible contained 7 prospective cohort studies, 4 prospective observational studies and 3 retrospective analyses, the sum of sample size being 13,286. The incidence of developing postoperative delirium (POD) ranged from 4.1 to $54.9 \%$.

\section{Risk of Bias and quality of evidence assessment}

Risk of bias assessment for eligible studies was summarized in Additional file 2, where all included studies were considered to be of low risk methodologically according to the Newcastle-Ottawa Scale. Quality of evidence assessment results using GRADE were presented in Additional file 3, in which GRADE certainty for metaanalysis result for variable hypertension was rated as moderate due to conflicting results of included studies, and the other results were considered to be of high confidence [33]. 


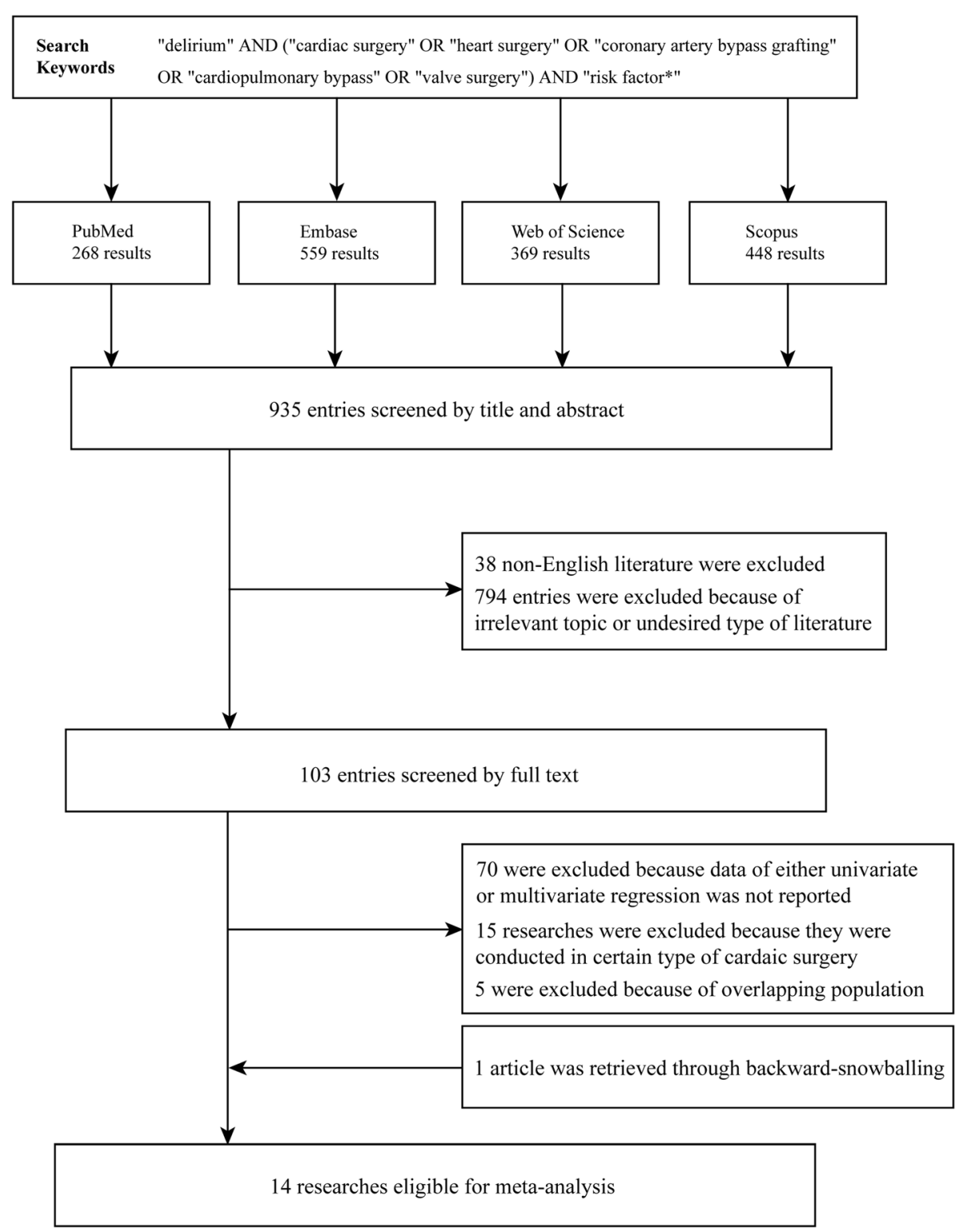

Fig. 1 The flowchart of literature selection process

\section{Preoperative risk factors}

In this category, 9 variables were eligible for metaanalysis, including age (increase by year or $>65$ years), carotid artery stenosis, diabetes, hypertension, left ventricular ejection fraction (LVEF) percentage, preoperative depression, New York Heart Association (NYHA) functional classification III or IV, mild cognitive impairment (MCI), and preoperative statins use.

Aging was identified as risk factor by nine researches, of which seven reported higher risk of POD when patients' age increased by year [21, 24, 26-28, 30, 31], while other two found age $>65$ was significantly associated with increased POD risk. Meta-analysis of these studies revealed significant increase of POD risk as patients' age increased.
(OR $=1.06,95 \% \mathrm{CI}:[1.04,1.08], \mathrm{I}^{2}=31 \%$ for age increase per year; $\mathrm{OR}=3.21,95 \% \mathrm{CI}$ : $[1.94,5.29], \mathrm{I}^{2}=68 \%$ if patients older than 65) (Fig. 2a, b).

Carotid artery stenosis was identified as risk factor by three researches [24-26], however, throughout inspection suggested there might be a mistake when reporting relevant data in one article as the data presented in table was exactly the same with its next row [26], so only two reports were eligible for meta-analysis, showing significantly increased risk in patients with carotid artery stenosis (OR $=1.72$, 95\% CI: [1.37, 2.16], $\left.\mathrm{I}^{2}=0 \%\right)$ (Fig. 2c).

Diabetes-related POD OR data in univariate regression was reported in eight studies [21-25, 28, 30, 31]. Metaanalysis of these report showed significantly increased 
Table 1 Main features of studies included

\begin{tabular}{|c|c|c|c|c|c|c|}
\hline $\begin{array}{l}\text { Study } \\
\text { Included }\end{array}$ & Design & Setting & $\begin{array}{l}\text { Sample } \\
\text { Size }\end{array}$ & Incidence & $\begin{array}{l}\text { Diagnosis } \\
\text { Standard }\end{array}$ & Risk Factors Identified \\
\hline $\begin{array}{l}\text { Burkhart } \\
2010[19]\end{array}$ & $\begin{array}{l}\text { Retrospective } \\
\text { analysis }\end{array}$ & $\begin{array}{l}\text { University Hospital } \\
\text { Basel, Basel, } \\
\text { Switzerland }\end{array}$ & 113 & $30 \%$ & CAM & $\begin{array}{l}\text { Max CRP, Fentanyl intraoperatively, Duration of } \\
\text { mechanical ventilation }\end{array}$ \\
\hline $\begin{array}{l}\text { Cai } 2020 \\
{[20]}\end{array}$ & $\begin{array}{l}\text { Prospective } \\
\text { cohort study }\end{array}$ & $\begin{array}{l}\text { Zhongshan Hospital, } \\
\text { Shanghai, China }\end{array}$ & 635 & $11.5 \%$ & CAM-ICU & $\begin{array}{l}\text { NT-proBNP, NYHA functional classification III or IV, } \\
\text { LVEF }\end{array}$ \\
\hline $\begin{array}{l}\text { Itagaki } \\
2020[21]\end{array}$ & $\begin{array}{l}\text { Retrospective } \\
\text { analysis }\end{array}$ & $\begin{array}{l}\text { The Cardiovascular } \\
\text { Institute, Tokyo, } \\
\text { Japan }\end{array}$ & 89 & $28.1 \%$ & ICDSC & Age, $\mathrm{MCl}$ (MoCA<26 points), Frailty (J-CHS3 points) \\
\hline $\begin{array}{l}\text { Katznelson } \\
2009[22]\end{array}$ & $\begin{array}{l}\text { Prospective } \\
\text { cohort study }\end{array}$ & $\begin{array}{l}\text { Toronto General } \\
\text { Hospital, Toronto, } \\
\text { Canada }\end{array}$ & 1059 & $11.5 \%$ & CAM-ICU & $\begin{array}{l}\text { Red blood cell transfusion, (> } 5 \text { units), Perioperative } \\
\text { intra-aortic balloon pump support, Preoperative de- } \\
\text { pression, Preoperative creatinine }>150 \mathrm{mM} \text {, Age } \geq 60 \\
\text { years, Combined CABG and valvular surgery. Pre- } \\
\text { operative administration of statins was found } \\
\text { protective }\end{array}$ \\
\hline $\begin{array}{l}\text { Kazmierski } \\
2010[23]\end{array}$ & $\begin{array}{l}\text { Prospective } \\
\text { cohort study }\end{array}$ & $\begin{array}{l}\text { WAM University } \\
\text { Hospital in Lodz, } \\
\text { Lodz, Poland }\end{array}$ & 563 & $16.3 \%$ & DSM-IV & $\begin{array}{l}\text { Age } \geq 65 \text { years, MMSE }<25 \text {, Major depression, } \\
\text { Anemia, AF, Intubation }>24 \mathrm{~h} \text {, pO2 }<60 \mathrm{mmHg}\end{array}$ \\
\hline $\begin{array}{l}\text { Kotfis } 2019 \\
{[24]}\end{array}$ & $\begin{array}{l}\text { Prospective } \\
\text { cohort study }\end{array}$ & $\begin{array}{l}\text { Hospital of } \\
\text { Pomeranian Medical } \\
\text { University, Szczecin, } \\
\text { Poland }\end{array}$ & 3178 & $15.8 \%$ & DSM-V & $\begin{array}{l}\text { Age, NYHA class III or IV, HbA1c, Creatinine at } \\
\text { admission, Extracardiac arteriopathy }\end{array}$ \\
\hline $\begin{array}{l}\text { Krzych } \\
2013[25]\end{array}$ & $\begin{array}{l}\text { Prospective } \\
\text { observational } \\
\text { study }\end{array}$ & $\begin{array}{l}\text { Upper Silesia Medical } \\
\text { Center, Katowice, } \\
\text { Poland }\end{array}$ & 5781 & $4.1 \%$ & DSM-IV & $\begin{array}{l}\text { Postoperative cerebral ischemia, blood transfusion, } \\
\text { Age }>65 \text { years, Carotid artery stenosis, Emergency } \\
\text { surgery, Fasting glucose level, } \Delta p O 2, \Delta \text { Hematocrit. } \\
\text { Hypertension was found protective }\end{array}$ \\
\hline $\begin{array}{l}\text { Norkiene } \\
2013[26]\end{array}$ & $\begin{array}{l}\text { Prospective } \\
\text { cohort study }\end{array}$ & $\begin{array}{l}\text { Vilnius University } \\
\text { Hospital, Vilnius, } \\
\text { Lithuania }\end{array}$ & 87 & $13.30 \%$ & ICDSC & $\begin{array}{l}\text { ICU stay, Duration of controlled mechanical } \\
\text { ventilation }\end{array}$ \\
\hline $\begin{array}{l}\text { Ogawa } \\
2018[27]\end{array}$ & $\begin{array}{l}\text { Prospective } \\
\text { cohort study }\end{array}$ & $\begin{array}{l}\text { Kobe University } \\
\text { Hospital, Kobe, Japan }\end{array}$ & 313 & $14.6 \%$ & ICDSC & 6MWD, ICU stay \\
\hline $\begin{array}{l}\text { Sabol } 2015 \\
{[28]}\end{array}$ & $\begin{array}{l}\text { Prospective } \\
\text { observational } \\
\text { study }\end{array}$ & $\begin{array}{l}\text { VUSCH, Kosice, } \\
\text { Slovakia }\end{array}$ & 250 & $20.8 \%$ & CAM-ICU & $\begin{array}{l}\text { Age, EuroSCORE II, CPB time, ACC time, Sufentanil } \\
\text { dose, Benzodiazepine administration, CABG }\end{array}$ \\
\hline $\begin{array}{l}\text { Sauër } 2017 \\
{[29]}\end{array}$ & $\begin{array}{l}\text { Retrospective } \\
\text { analysis }\end{array}$ & $\begin{array}{l}\text { University Medical } \\
\text { Center Utrecht, } \\
\text { Utrecht, the } \\
\text { Netherlands }\end{array}$ & 184 & $12.5 \%$ & CAM-ICU & Trailmaking test $\mathrm{A}$ \\
\hline $\begin{array}{l}\text { Smulter } \\
2013[30]\end{array}$ & $\begin{array}{l}\text { Prospective } \\
\text { observational } \\
\text { study }\end{array}$ & $\begin{array}{l}\text { Umeå University } \\
\text { Hospital, Umeå, } \\
\text { Sweden }\end{array}$ & 142 & $54.9 \%$ & DSM-IV & $\begin{array}{l}\text { NRS pain, Diabetes, Oxygen saturation peripheral, } \\
\text { Combined surgical procedure, Volume load (blood } \\
\text { excluded), Ventilator time, Sodium concentration in } \\
\text { ICU }\end{array}$ \\
\hline $\begin{array}{l}\text { Tully } 2010 \\
\text { [31] }\end{array}$ & $\begin{array}{l}\text { Prospective } \\
\text { cohort study }\end{array}$ & $\begin{array}{l}\text { Flinders Medical } \\
\text { Centre, Adelaide, } \\
\text { Australia }\end{array}$ & 158 & $31 \%$ & $\begin{array}{l}\text { Delirium Symptom } \\
\text { Interview (DSI) } \\
\text { based on DSM-IV }\end{array}$ & $\begin{array}{l}\text { ACC time, hemoglobin, Major depressive disorder, } \\
\text { Psychotropic/anti-cholinergic drug use }\end{array}$ \\
\hline $\begin{array}{l}\text { Wesselink } \\
2015[32]\end{array}$ & $\begin{array}{l}\text { Prospective } \\
\text { observational } \\
\text { study }\end{array}$ & $\begin{array}{l}\text { University Medical } \\
\text { Center Utrecht, } \\
\text { Utrecht, the } \\
\text { Netherlands }\end{array}$ & 734 & $13 \%$ & $\begin{array}{l}\text { CAM and CAM- } \\
\text { ICU }\end{array}$ & $\mathrm{MAP}<60 \mathrm{mmHg}$ \\
\hline
\end{tabular}

6MWD 6-min walking distance, $A C C$ aortic cross-clamping, $A F$ atrial fibrillation, $C A B G$ coronary artery bypass grafting, $C A M$ Confusion Assessment Method, $C P B$ cardiopulmonary bypass, HbA1c glycated hemoglobin, LVEF left ventricular ejection fraction, DSM Diagnostic and Statistical Manual of Mental Disorders, ICU intensive care unit, ICDSC Intensive Care Delirium Screening Checklist, MAP mean arterial pressure, Max CRP maximum value of C-reactive protein postoperatively, MCI mild cognitive impairment, MMSE Mini-Mental State Examination, MoCA Montreal Cognitive Assessment, NRS Numeric Rating Scale, NT-proBNP N-terminal prohormone of brain natriuretic peptide, NYHA New York Heart Association, $p O 2$ arterial oxygen partial pressure. $\triangle$ : intraoperative fluctuation (max-min)

OR in patients with diabetes $(\mathrm{OR}=1.61,95 \% \mathrm{CI}$ : [1.40, 1.84], $\mathrm{I}^{2}=0 \%$ ) (Fig. 2d).

Hypertension was found associated with lower OR of POD in one study [25], while among other studies the relationship was insignificant [21-26, 28, 31]. The result of our meta-analysis supported the latter conclusion ( $\mathrm{OR}=1.03,95 \% \mathrm{CI}$ : $\left.[0.66,1.60], \mathrm{I}^{2}=84 \%\right)$ (Fig. 2e). 


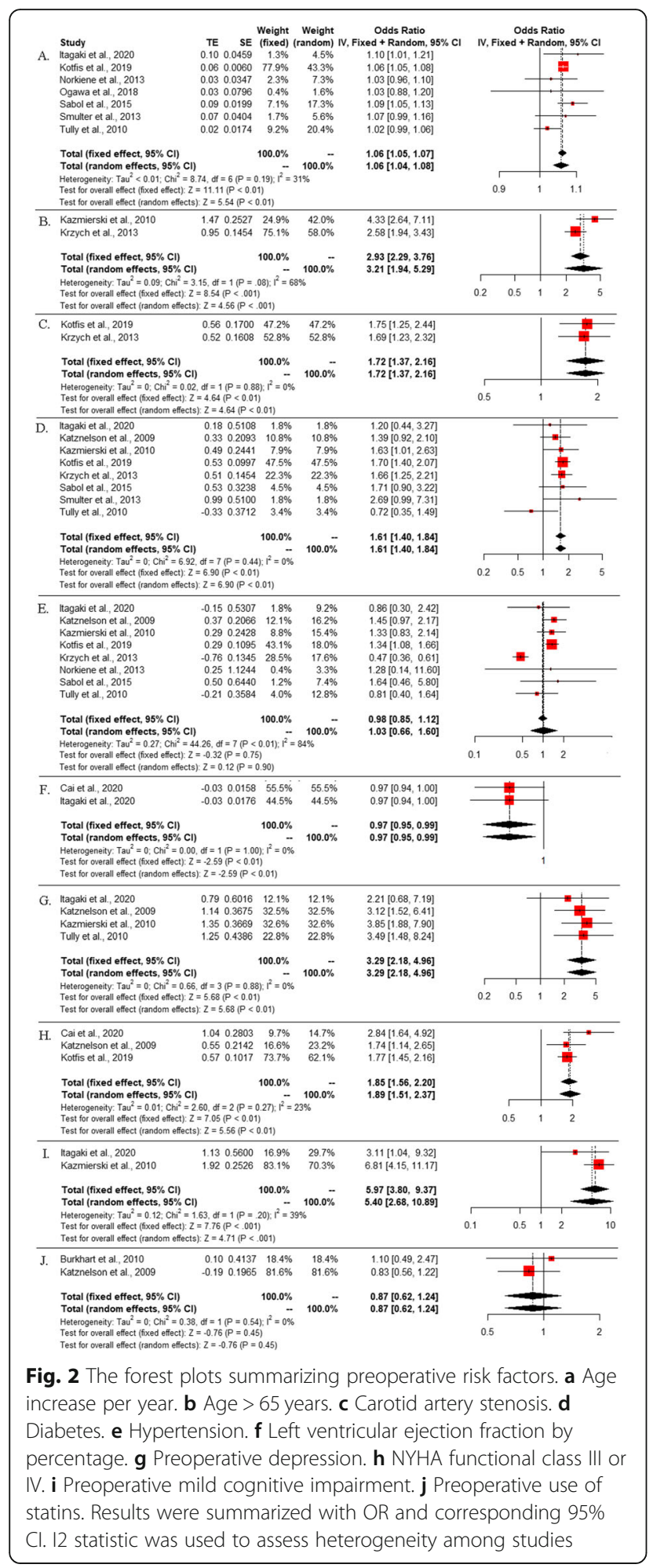

Heart-function related risk factors were also identified within eligible literature. LVEF increase by percentage was found to be protective by Cai et al. [20], and was supported by our meta-analysis together with data reported by Itagaki et al. [21] $(\mathrm{OR}=0.97,95 \% \mathrm{CI}$ : [0.95,
0.99], $\mathrm{I}^{2}=0 \%$ ) (Fig. 2f), while three researches reported NYHA functional classification III or IV was associated with significantly increased OR of POD [20, 22, 24] $\left(\mathrm{OR}=1.89,95 \%\right.$ CI: $\left.[1.51,2.37], \mathrm{I}^{2}=23 \%\right)$ (Fig. 2h).

Preoperative depression was identified as risk factor in three studies [22, 23, 31]. After combining the three studies with data provided by another report [21], metaanalysis showed patients with preoperative depression suffered from higher risk of POD $(\mathrm{OR}=3.29,95 \% \mathrm{CI}$ : $[2.18,4.96], \mathrm{I}^{2}=0 \%$ ) (Fig. 2g). Preoperative mild cognitive impairment was identified as risk factor in two studies [21, 23], where the term was defined as Montreal Cognitive Assessment (MoCA) $<26$ or Mini-Mental State Examination (MMSE) $<25$, respectively. Our metaanalysis of these two studies showed preoperative cognitive impairment was associated with increased risk of POD $\left(\mathrm{OR}=5.40,95 \%\right.$ CI: $[2.68,10.89], \mathrm{I}^{2}=39 \%$ ) (Fig. 2i).

Preoperative use of statin was found to be a protective factor by Katznelson et al. [22]. However, meta-analysis combining data from another report [19] failed to support the conclusion $\left(\mathrm{OR}=0.87,95 \% \mathrm{CI}\right.$ : $[0.62,1.24], \mathrm{I}^{2}=$ 0\%) (Fig. 2j).

\section{Intraoperative and postoperative risk factors}

In this category, 3 variables were eligible for metaanalysis, including aortic cross clamp (ACC) time (per minute), intensive care unit (ICU) stay (per day) and mechanical ventilation time (per hour).

ACC time related POD OR data was reported in four researches $[23,26,28,31]$. Pooled analysis showed that for every one-minute increase in ACC time, the OR for POD increased by $1 \%\left(\mathrm{OR}=1.01,95 \% \mathrm{CI}\right.$ : $\left.[1.00,1.02], \mathrm{I}^{2}=51 \%\right)$ (Fig. 3a). However, in test for overall effect the variable failed to achieve statistical significance $(p=0.06)$.

Two researches identified length of ICU stay was associated with increased OR of POD [26, 27]. When combined with data from other two studies [21, 28], metaanalysis supported the conclusion, showing for every one more day of ICU stay was associated with $40 \%$ increase OR of POD (OR $=1.40,95 \%$ CI: $\left.[1.00,1.94], \mathrm{I}^{2}=60 \%\right)$ (Fig. 3b). Finally, meta-analysis using data from four studies also showed increased time of mechanical ventilation (per hour) was associated with higher risk of POD $[19,21,26,30]\left(\mathrm{OR}=1.11,95 \%\right.$ CI: $[1.02,1.21], \mathrm{I}^{2}=$ 66\%) (Fig. 3c).

\section{Sensitivity analysis and funnel plot analysis}

In Meta-analyses regarding age (per year), diabetes and hypertension as risk factors for POD after cardiac surgery, sensitivity analysis and funnel plot analysis was performed. In the age (per year) analysis, sensitivity analysis showed no individual research had major impact on final pooled result (Fig. 4a), however, funnel plot analysis 


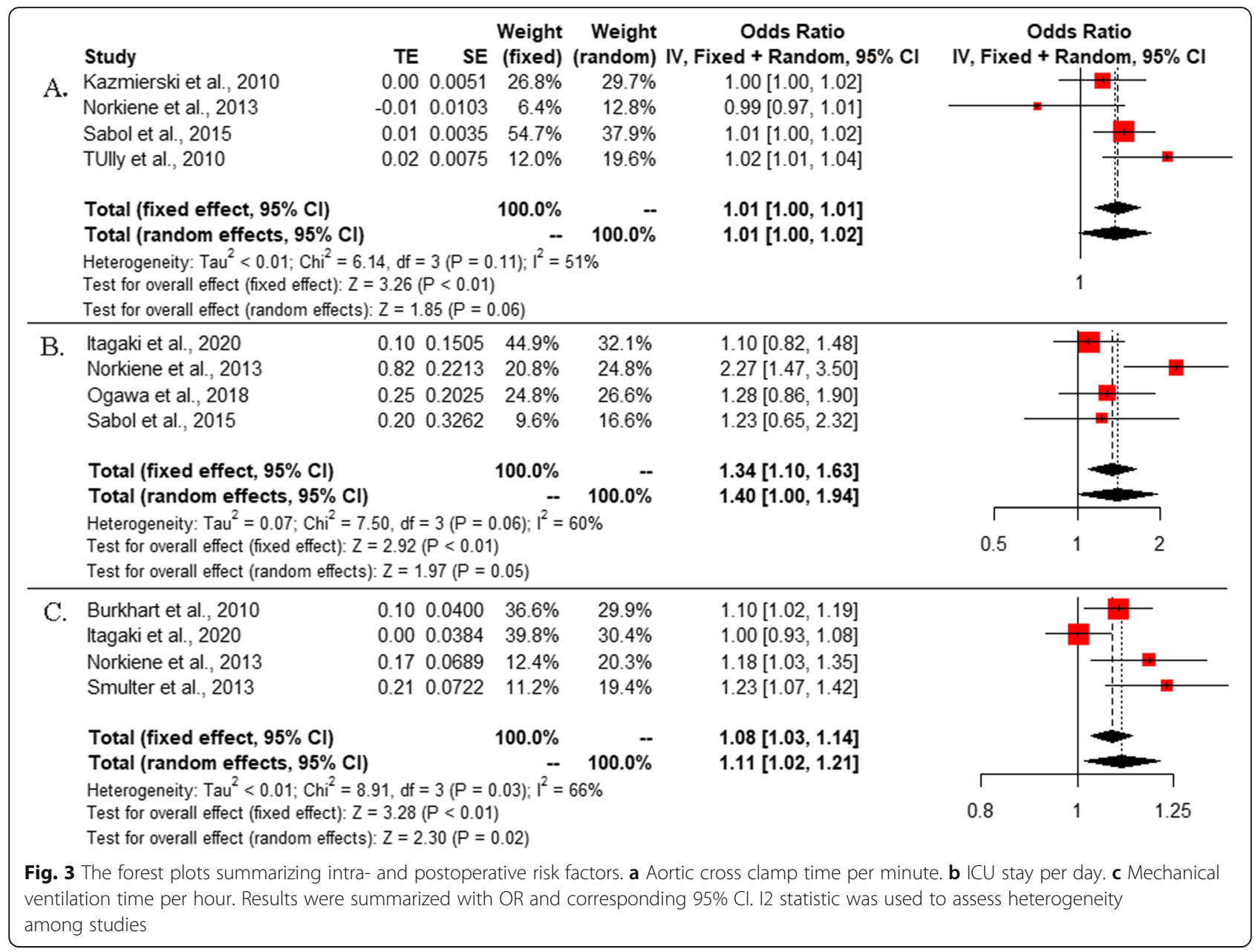

revealed potential asymmetry (Fig. 4b). In the diabetes analysis, sensitivity analysis returned similar result (Fig. 4c) and funnel plot was of good symmetry (Fig. 4d). In the hypertension analysis, funnel plot analysis revealed the presence of asymmetry (Fig. 4f), and sensitivity analysis showed the study by Krzych et al. had a major impact on result of meta-analysis [25] (Fig. 4e).

\section{Post-hoc analysis}

To evaluate the impact of the study by Krzych et al. on the meta-analysis of hypertension variable, a post-hoc analysis was conducted by excluding this study from the analysis and a new forest plot was formed. The post-hoc analysis suggested hypertension was associated with increased risk of POD after cardiac surgery $(\mathrm{OR}=1.31$, 95\% CI: $[1.12,1.55], \mathrm{I}^{2}=0 \%$ ) (Fig. 4g). After excluding the study, sensitivity analysis showed stable result (Fig. 4h) and funnel plot symmetry was restored (Fig. 4i). We also noted that after excluding the study, $\mathrm{I}^{2}$ statistic measuring heterogeneity turned to $0 \%$, compared to the previous value of $84 \%$, suggesting the study by Krzych et al. was the primary cause of heterogeneity.

\section{Discussion}

To summarize, through this meta-analysis, we identified a series of risk factors for POD after cardiac surgery including older age, carotid artery stenosis, diabetes, preoperative depression or mild cognitive impairment, NYHA functional class III or IV, length of ICU-stay or mechanical ventilation. We also identified LVEF as a protective factor, and preoperative statins use not significantly associated with development of POD. We hope the information provided by our meta-analysis can be used to assist the daily nursing practice of cardiac surgery ICU, allowing patients with high risk of developing delirium to be identified in advance.

In our study, all risk factors were empirically classified into preoperative, intraoperative and postoperative risk factors. The aim of doing so was to make the result of this study easier utilized in practical nursing work. Surprisingly we found that among preoperative analyses, the heterogeneity among studies was generally lower than the heterogeneity of intra- and postoperative risk factors, which could potentially be explained as preoperative risk factors have similar effect in general population while 


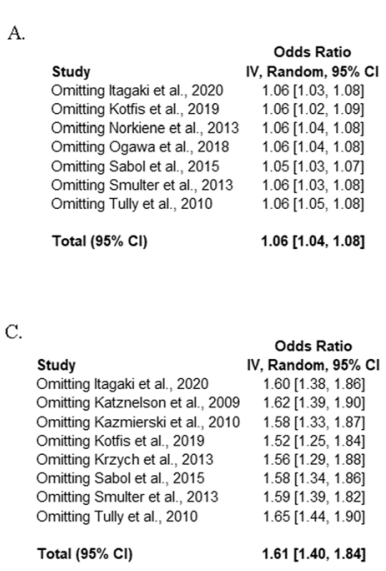

E.

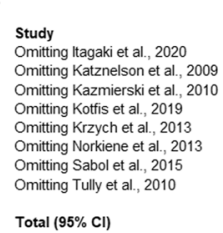

Odds Ratio Random, $95 \%$ C $0.97[0.58,1.61]$ $0.98[0.59,1.64]$ $0.98[0.58,1.64]$ $.31[1.11,1.55]$ $1.02[0.65,1.61]$ $1.07[0.65,1.75]$ $1.03[0.66,1.60]$

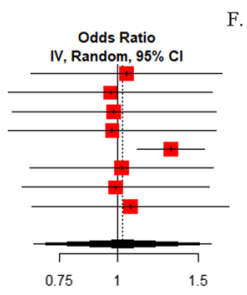

G.

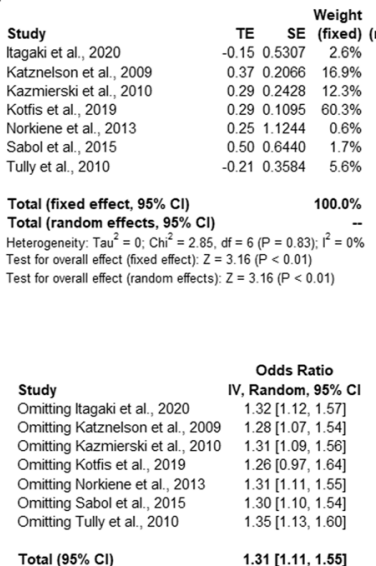
Katznelson et al. Kazmierski et al., 20100
Kotfis et al., 2019 orketal, 2019 Sabol et al., 2015 Total (fixed effect, $95 \% \mathrm{Cl}$ ) Total (random effects, $95 \%$
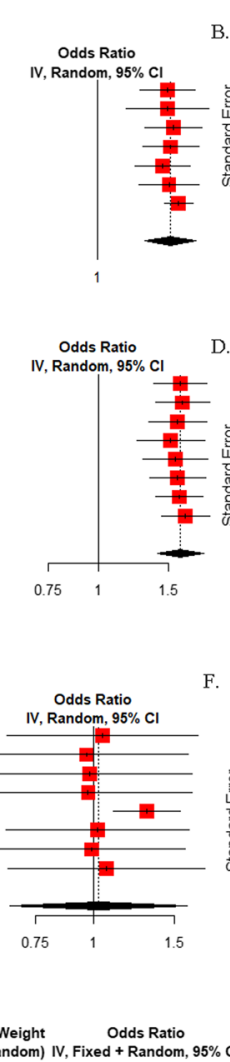
$0.86[0.30,2.42]$
$1.45[0.93,2.77$ $0.86[0.30,2.42]$
$1.45[0.97,2.17]$ $1.45[0.97,2.17]$
$1.33[0.83,2.14]$ $1.34[1.08,1.66]$
$1.28[0.14,11.60]$ $1.28[0.14,11.60]$ $1.64[0.46,5.80]$
$0.81[0.40,1.64]$ $1.31[1.11,1.55]$ $1.31[1.11,1.55]$

H.

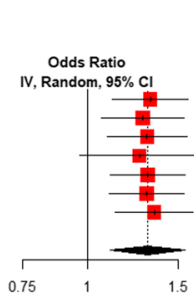

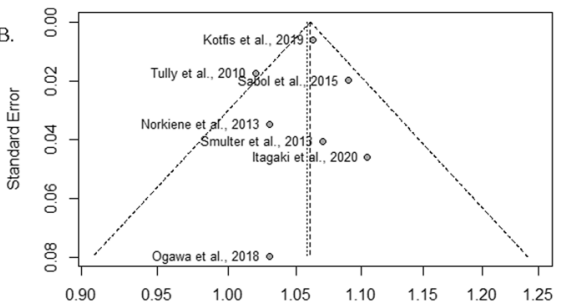

Odds Ratio
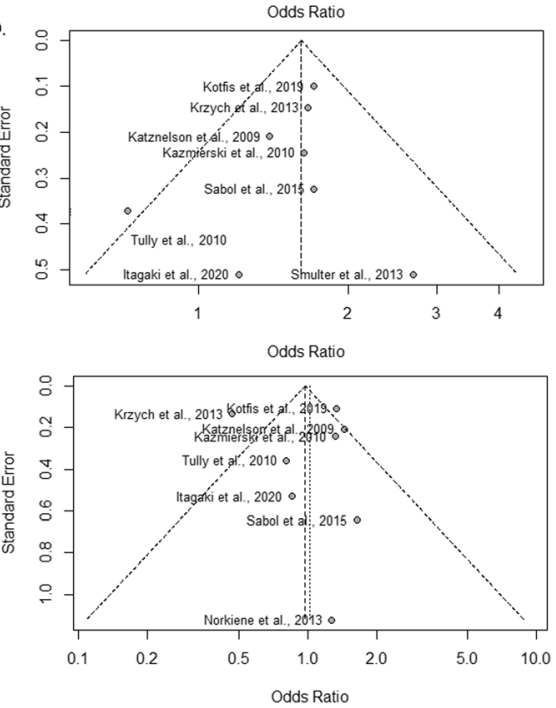
Odds Ratio
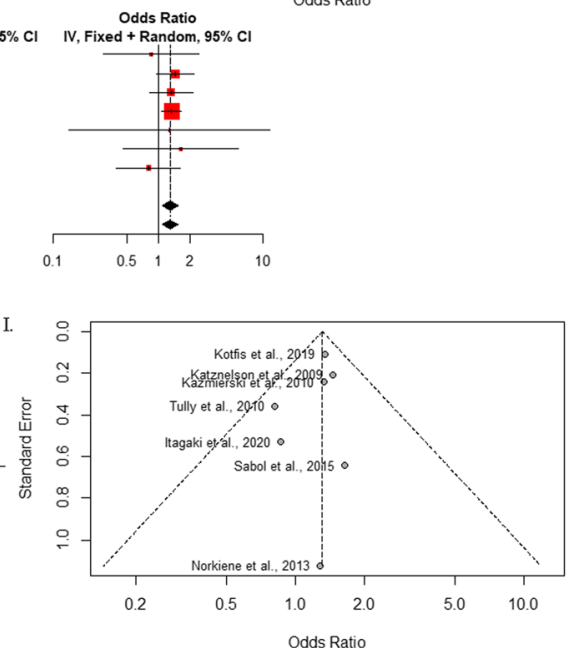

Fig. 4 Sensitivity analysis and funnel plot of analyses containing more than 4 studies. a Sensitivity analysis for age increase per year. b Funnel plot for age increase per year. c Sensitivity analysis for diabetes. d Funnel plot for diabetes. e Sensitivity analysis for hypertension. $\mathbf{f}$ Funnel plot for hypertension. $\mathbf{g}$ Forest plot of hypertension as risk factor after excluding the study that had major impact to pooled result. $\mathbf{h}$ Sensitivity analysis for hypertension after excluding the study that had major impact to pooled result. i Funnel plot for hypertension after excluding the study that had major impact to pooled result

the effects of intra-and postoperative risk factors are different due to the difference in medical practice among different hospitals. We also noted these identified risk factors fell into four partly overlapping groups: risk factors associated with general condition such as age and diabetes; ischemic condition related risk factors such as carotid artery stenosis, NYHA III or IV and LVEF; cognition-related risk factors such as preoperative depression and mild cognitive impairment; and intervention related risk factors such as mechanical ventilation time and length of ICU stay. These features may enlighten future research in POD etiology. However, it is important to note that none of these identified risk factors can be declared to be causative at present since the 
mechanism and direct cause of POD remains to be determined.

In order to interpret the results of our meta-analysis in context of other evidence, we conduct a search on PubMed with the keywords "delirium cardiac surgery meta-analysis". In the study by Vallabhajosyula et al. evaluating the effect of statins on POD prevention, meta-analysis of 6 included studies with 4382 patients underwent cardiac surgery (and statins were used in 2321 of them) concluded that statin therapy did not benefit delirium prevention, which was consistent with our results [13]. In the systemic review by Greaves et al. specifically summarize risk factors for POD following coronary artery bypass grafting surgery, cognitive impairment was found to show the largest effect, followed by stroke history and depression. Diabetes and hypertension were also significantly associated with higher risk of POD [34]. In transcatheter aortic valve implantation, risk factors for POD identified by Tilley et al. included coronary artery disease and hypertension, while NYHA IIIIV, LVEF, age and diabetes were not statistically significant [35]. The partly-overlapping conclusions of these studies, including our meta-analysis, strongly suggested not only existence of association between the identified risk factors and POD but also the difference in nature of distinct surgery types.

For hypertension variable, the initial meta-analysis revealed no statistically significant association between the variable and POD occurrence. However, when the forest plot and corresponding funnel plot were inspected by the authors, we found the study by Krzych et al. may have a major impact to the result of analysis, as indicated by the leave-one-out sensitivity analysis, and caused asymmetry in funnel plot. A post-hoc analysis was decided to investigate if there was an association between hypertension and POD occurrence when the study by Krzych et al. was excluded. Interestingly hypertension was found to be a significant risk factor in the post-hoc analysis $\left(\mathrm{OR}=1.31,95 \% \mathrm{CI}\right.$ : $[1.12,1.55], \mathrm{I}^{2}=$ 0\%) (Fig. 4g). We believed the impact of Krzych study was because of its relatively large sample size and conflicting direction of effect. Besides, potential funnel plot asymmetry was also noticed in analysis of hypertension variable. We believed the presence of small-study effect might not be a satisfying explanation since all studies except the Krzych 2013 study located somewhere near the line of symmetry of funnel plot. Generally, study with lower standard error gives more accurate estimation for effect, while in this analysis a major disagreement among large studies presented. The inclusion of Krzych study on hypertension variable made the non-significant result of the initial analysis less robust, while result from the post-hoc analysis needed to be interpreted with more caution since the exclusion was only based on sensitivity analysis and funnel plot imbalance, when the study was rated of low risk of bias methodologically (8 stars with Newcastle-Ottawa Scale), resulting in a lower level of evidence of the post-hoc analysis result. Here we chose not to report hypertension as a risk factor for POD and believed further research is needed regarding this question.

Finally, it is important to specify potential limitations of this study. Due to the strict inclusion criteria, only a few reports were considered eligible for analysis, making this study at risk of omitting potentially valuable information. However, due to the mentioned reason, we believed it was a necessary sacrifice and hereby strongly advice researchers to present both the result of univariate and multivariate regression. Second, the risk factors identified might contain confounding factors. For example, length of ICU stay could be a confounder of mechanical ventilation time, dose of sedative medication and so on, while these variables were left unadjusted. Third, considering the retrospective nature of certain included studies and dropouts in prospective cohort studies, selection bias might present. Fourth, the diagnosis standard of comorbidities such as hypertension, diabetes and preoperative depression might be not same among individual studies.

\section{Conclusion}

In conclusion, in this meta-analysis, 8 risk factors and 1 protective factor were identified in 14 researches. Further research remains necessary to validate these conclusions and to investigate the underlying mechanisms.

Abbreviations

ACC: Aortic cross clamp; CAM: Confusion Assessment Method; Cl: Confidence interval; DSM: Diagnostic and Statistical Manual of Mental Disorders; ICDS

C: Intensive Care Delirium Screening Checklist; ICU: Intensive Care Unit; LVEF: Left ventricular ejection fraction; MCl: Mild cognitive impairment; MMSE: Mini-Mental State Examination; MoCA: Montreal Cognitive Assessment; NYHA: New York Heart Association; OR: Odds ratio; POD: Postoperative delirium

\section{Supplementary Information}

The online version contains supplementary material available at https://doi. org/10.1186/s13019-021-01496-w.

\section{Additional file 1. Supplementary}

Additional file 2. Risk of bias assessment for included studies using Newcastle-Ottawa Scale. Studies were considered to be at low risk if rated 7 stars or above, moderate risk if rated 4-6 stars, and high risk if less than 4 stars.

Additional file 3. Level of evidence assessment of meta-analysis results using Grading of Recommendations, Assessment, Development and Evaluations (GRADE). 


\section{Authors' contributions}

HYC collected and analyzed the data and wrote the manuscript; LM and HJH designed the study and revised the manuscript; YLO and JL collected the data. All authors read and approved the final manuscript.

\section{Funding}

This study was supported by the construction and practice of the prevention and treatment mode of stress injury in primary hospitals based on "Internet +" [grant number 20200769]. The funding just did the financial support.

\section{Availability of data and materials}

All data generated or analysed during this study are included in this published article and its supplementary information files.

\section{Declarations}

Ethics approval and consent to participate

This study did not contain any human participates and the ethics approval and inform consent are not applicable.

\section{Consent for publication}

Not applicable.

\section{Competing interests}

The authors declare that they have no competing interests.

\section{Author details}

'Education and Training Department, The First Affiliated Hospital of University of South China, Hengyang, China. ${ }^{2}$ Department of Cardiothoracic Surgery, The First Affiliated Hospital of University of South China, Hengyang, China. ${ }^{3}$ Nursing Department, The First Affiliated Hospital of University of South China, Hengyang, China.

Received: 10 November 2020 Accepted: 11 April 2021

Published online: 26 April 2021

\section{References}

1. Egerton N, Kay JH. Psychological disturbances associated with open heart surgery. Br J Psychiatry. 1964;1 10(466):433-9. https://doi.org/10.1192/bjp.11 0.466 .433

2. O'Neal JB, Shaw AD. Predicting, preventing, and identifying delirium after cardiac surgery. Perioper Med. 2016;5:7. https://doi.org/10.1186/s13741-0160032-5.

3. European Delirium A, American DS. The DSM-5 criteria, level of arousal and delirium diagnosis: inclusiveness is safer. BMC Med. 2014;12(1):141. https:// doi.org/10.1186/s12916-014-0141-2.

4. Rengel KF, Pandharipande PP, Hughes CG. Postoperative delirium. Presse Med. 2018:47(4 Pt 2):e53-64. https://doi.org/10.1016/j.lpm.2018.03.012.

5. Peritogiannis V, Bolosi M, Lixouriotis C, Rizos DV. Recent insights on prevalence and Corelations of hypoactive Delirium. Behav Neurol. 2015; 2015:416792-11. https://doi.org/10.1155/2015/416792.

6. Lundström M, Edlund A, Karlsson S, Brännström B, Bucht G, Gustafson Y. A multifactorial intervention program reduces the duration of delirium, length of hospitalization, and mortality in delirious patients. J Am Geriatr Soc. 2005; 53(4):622-8. https://doi.org/10.1111/j.1532-5415.2005.53210.x.

7. Bickel H, Gradinger R, Kochs E, Förstl H. High risk of cognitive and functional decline after postoperative delirium. A three-year prospective study. Dement Geriatr Cogn Disord. 2008;26(1):26-31. https://doi.org/10.1159/ 000140804.

8. Saczynski JS, Marcantonio ER, Quach L, Fong TG, Gross A, Inouye SK, et al. Cognitive trajectories after postoperative delirium. N Engl J Med. 2012; 367(1):30-9. https://doi.org/10.1056/NEJMoa1112923.

9. Järvelä K, Porkkala H, Karlsson S, Martikainen T, Selander T, Bendel S. Postoperative Delirium in cardiac surgery patients. J Cardiothorac Vasc Anesth. 2018;32(4):1597-602. https://doi.org/10.1053/j.jvca.2017.12.030.

10. Brown CH. Delirium in the cardiac surgical ICU. Curr Opin Anaesthesiol. 2014;27(2):117-22. https://doi.org/10.1097/ACO.0000000000000061.

11. Liu X, Xie G, Zhang K, Song S, Song F, Jin Y, et al. Dexmedetomidine vs propofol sedation reduces delirium in patients after cardiac surgery: a metaanalysis with trial sequential analysis of randomized controlled trials. J Crit Care. 2017;38:190-6. https://doi.org/10.1016/j.jcrc.2016.10.026.
12. Shehabi Y, Howe BD, Bellomo R, Arabi YM, Bailey M, Bass FE, et al. Early sedation with Dexmedetomidine in critically ill patients. N Engl J Med. 2019; 380(26):2506-17. https://doi.org/10.1056/NEJMoa1904710.

13. Vallabhajosyula S, Kanmanthareddy A, Erwin PJ, Esterbrooks DJ, Morrow LE. Role of statins in delirium prevention in critical ill and cardiac surgery patients: a systematic review and meta-analysis. J Crit Care. 2017;37:189-96. https://doi.org/10.1016/j.jcrc.2016.09.025.

14. Garrett KM. Best practices for managing pain, sedation, and Delirium in the mechanically ventilated patient. Crit Care Nurs Clin North Am. 2016;28(4): 437-50. https://doi.org/10.1016/j.cnc.2016.07.004.

15. Koster S, Hensens AG, Schuurmans MJ, van der Palen J. Risk factors of delirium after cardiac surgery: a systematic review. Eur J Cardiovasc Nurs. 2011;10(4):197-204. https://doi.org/10.1016/j.ejcnurse.2010.09.001.

16. Lin $Y$, Chen J, Wang Z. Meta-analysis of factors which influence delirium following cardiac surgery. J Card Surg. 2012;27(4):481-92. https://doi.org/1 0.1111/j.1540-8191.2012.01472.x.

17. Balduzzi $S$, Rücker $G$, Schwarzer $G$. How to perform a meta-analysis with $R$ : a practical tutorial. Evid Based Ment Health. 2019;22(4):153-60. https://doi. org/10.1136/ebmental-2019-300117.

18. Wells G, Shea B, O'Connell D, Peterson J, Welch V, Losos M, et al. The Newcastle-Ottawa Scale (NOS) for assessing the quality of non-randomized studies in meta-analysis. 2000.

19. Burkhart CS, Dell-Kuster S, Gamberini M, Moeckli A, Grapow M, Filipovic M, et al. Modifiable and nonmodifiable risk factors for postoperative delirium after cardiac surgery with cardiopulmonary bypass. J Cardiothorac Vasc Anesth. 2010;24(4):555-9. https://doi.org/10.1053/j.jvca.2010.01.003.

20. Cai S, Latour JM, Lin Y, Pan W, Zheng J, Xue Y, et al. Preoperative cardiac function parameters as valuable predictors for nurses to recognise delirium after cardiac surgery: a prospective cohort study. Eur J Cardiovasc Nurs. 2020;19(4):310-9. https://doi.org/10.1177/1474515119886155.

21. Itagaki A, Sakurada K, Matsuhama M, Yajima J, Yamashita T, Kohzuki M. Impact of frailty and mild cognitive impairment on delirium after cardiac surgery in older patients. J Cardiol. 2020;76(2):147-53. https://doi.org/10.101 6/j.jjcc.2020.02.007.

22. Katznelson R, Djaiani GN, Borger MA, Friedman Z, Abbey SE, Fedorko L, et al. Preoperative use of statins is associated with reduced early delirium rates after cardiac surgery. Anesthesiology. 2009;110(1):67-73. https://doi.org/10.1 097/ALN.0b013e318190b4d9.

23. Kazmierski J, Kowman M, Banach M, Fendler W, Okonski P, Banys A, et al. Incidence and predictors of delirium after cardiac surgery: results from the IPDACS study. J Psychosom Res. 2010;69(2):179-85. https://doi.org/10.1016/j. jpsychores.2010.02.009

24. Kotfis K, Szylinska A, Listewnik M, Brykczynski M, Ely EW, Rotter I. Diabetes and elevated preoperative $\mathrm{HbA} 1 \mathrm{c}$ level as risk factors for postoperative delirium after cardiac surgery: an observational cohort study. Neuropsychiatr Dis Treat. 2019;15:511-21. https://doi.org/10.2147/NDT.S196973.

25. Krzych ப, Wybraniec MT, Krupka-Matuszczyk I, Skrzypek M, Bolkowska A, Wilczynski $M$, et al. Complex assessment of the incidence and risk factors of delirium in a large cohort of cardiac surgery patients: a single-center 6-year experience. Biomed Res Int. 2013;2013:835850-9. https//doi.org/10.1155/2013/835850.

26. Norkiene I, Ringaitiene D, Kuzminskaite V, Sipylaite J. Incidence and risk factors of early delirium after cardiac surgery. Biomed Res Int. 2013;2013: 323491-5. https://doi.org/10.1155/2013/323491.

27. Ogawa M, Izawa KP, Satomi-Kobayashi S, Kitamura A, Tsuboi Y, Komaki K, et al. Preoperative exercise capacity is associated with the prevalence of postoperative delirium in elective cardiac surgery. Aging Clin Exp Res. 2018; 30(1):27-34. https://doi.org/10.1007/s40520-017-0736-5.

28. Sabol F, Bilý B, Artemiou P, Kolesár A, Török P, Bilecová-Rabajdová M, et al. Incidence and risk factors of delirium in patients after cardiac surgery: modifiable and non-modifiable factors. Cor et Vasa. 2015;57(3):e168-e75. https://doi.org/10.1016/j.crvasa.2015.01.004.

29. Sauer AC, Veldhuijzen DS, Ottens TH, Slooter AJC, Kalkman CJ, van Dijk D. Association between delirium and cognitive change after cardiac surgery. $\mathrm{Br}$ J Anaesth. 2017;119(2):308-15. https://doi.org/10.1093/bja/aex053.

30. Smulter N, Lingehall HC, Gustafson Y, Olofsson B, Engstrom KG. Delirium after cardiac surgery: incidence and risk factors. Interact Cardiovasc Thorac Surg. 2013;17(5):790-6. https://doi.org/10.1093/icvts/ivt323.

31. Tully PJ, Baker RA, Winefield HR, Turnbull DA. Depression, anxiety disorders and type D personality as risk factors for delirium after cardiac surgery. Aust N Z J Psychiatry. 2010:44(11):1005-11. https://doi.org/10.3109/00048674.201 0.495053 . 
32. Wesselink EM, Kappen TH, van Klei WA, Dieleman JM, van Dijk D, Slooter AJ. Intraoperative hypotension and delirium after on-pump cardiac surgery. Br J Anaesth. 2015;115(3):427-33. https://doi.org/10.1093/bja/aev256.

33. BMJ Best Practice. https://bestpractice.bmj.com/info/toolkit/learn-ebm/whatis-grade/ Accessed 24 Nov 2020.

34. Greaves D, Psaltis PJ, Davis DHJ, Ross TJ, Ghezzi ES, Lampit A, et al. Risk factors for Delirium and cognitive decline following coronary artery bypass grafting surgery: a systematic review and Meta-analysis. J Am Heart Assoc. 2020;9(22):e017275. https://doi.org/10.1161/JAHA.120.017275.

35. Tilley E, Psaltis PJ, Loetscher T, Davis DH, Harrison SL, Kim S, et al. Metaanalysis of prevalence and risk factors for Delirium after Transcatheter aortic valve implantation. Am J Cardiol. 2018;122(11):1917-23. https://doi.org/10.1 016/j.amjcard.2018.08.037.

\section{Publisher's Note}

Springer Nature remains neutral with regard to jurisdictional claims in published maps and institutional affiliations.

Ready to submit your research? Choose BMC and benefit from:

- fast, convenient online submission

- thorough peer review by experienced researchers in your field

- rapid publication on acceptance

- support for research data, including large and complex data types

- gold Open Access which fosters wider collaboration and increased citations

- maximum visibility for your research: over $100 \mathrm{M}$ website views per year

At BMC, research is always in progress.

Learn more biomedcentral.com/submissions 